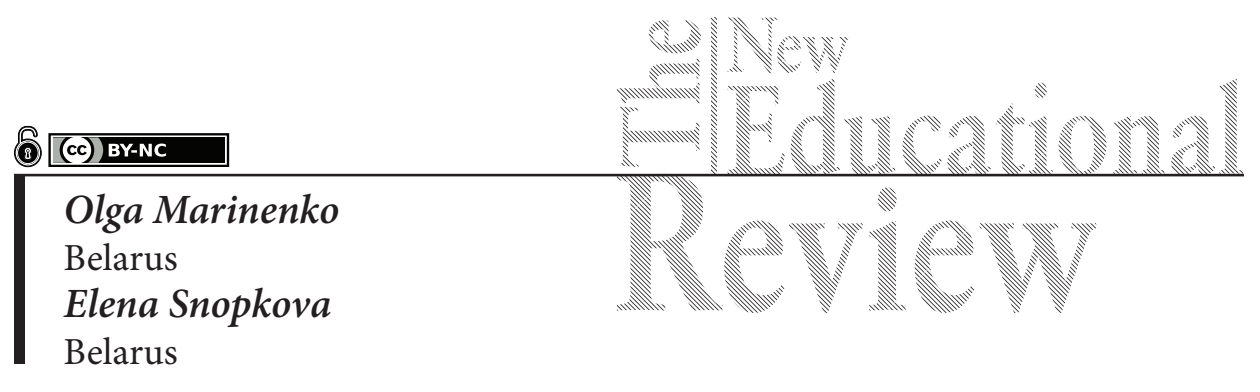

\title{
Challenges Facing International Students During Study in Belarus
}

DOI: 10.15804/tner.2019.58.4.11

\begin{abstract}
This research aims to identify and rank the problems which international students face during study in Belarus. The main method was descriptive research conceptualized within sojourner theory. Preliminary interviews followed by a survey $(\mathrm{N}=300)$ revealed that the sojourners' problems were in the following order, from major to minor: (a) psychological and health-related challenges, primarily, homesickness and health disorders; (b) academic challenges, such as the new educational system and taking exams; (c) sociocultural challenges, especially communication with native speakers; (d) general living challenges. To prevent and solve these problems, the study provides experimentally based recommendations how to foster a supporting learning environment.
\end{abstract}

Key words: study abroad, sojourners, international students' challenges, supporting learning environment.

\section{Introduction}

International students are an increasingly important source of diversity in colleges and universities worldwide (Sonari, 1994). They contribute to internationalization of higher education institutions and enhance students' and faculties' awareness and appreciation of other nations and cultures. This has resulted in the fact that currently the number of international students is constantly rising in most countries, including Belarus (Education in the Republic of Belarus, 2016). 
Meanwhile, studying abroad is challenging and problematic for international students who often face a host of issues and concerns such as psychological and somatic disorders, academic and language difficulties which are exacerbated by social and cultural differences between their native countries and the culture of the new country (Gebhard, 2012). Experiencing study abroad is considered an important psychological process due to its effects on the performance and functioning of international newcomers. Regarding sojourners' physical and emotional states, research documented a number of particular problems: isolation and loneliness, homesickness and emotional exhaustion, anxiety, recurrent headaches and insomnia (Abe, Talbot, \& Geelhoed, 1998; Sonari, 1994; Yan \& Sendall, 2016).

In most studies issues related to overseas students' new language proficiency were reported to be their most concerning problem (Alsahafi \& Shin, 2017). At the same time, a number of findings argued that the problem was wider and the whole educational system caused difficulties during study abroad (Carroll \& Ryan, 2005). Particularly, Sonari's research (1994) reported the following educational encounters: compulsory class attendance, examinations, choosing courses, using the library, grading system, etc.

Unfamiliar social and cultural environments also affect both the state of the overseas students and their learning outcomes, and previous research substantiated a number of sociocultural difficulties complicating study abroad: communication with locals, understanding slang, visiting social events, differences in communication patterns, etc. (Ward \& Kennedy, 1999). Sociocultural barriers exacerbate sojourners' general living problems, such as shopping, cooking, etc., because most of the students were not experienced in living alone in their home countries. (Sam, 2001).

\section{Research Focus}

Despite a significant number of studies, researchers still have not reached a stable consensus on "the magnitude of adjustment challenges" and this problem "needs further exploration" (Wenhua \& Zhe, 2013, p. 405). Thus, two main reasons have grounded the current research. First, the majority of studies on the problems of international students have been completed in English-speaking countries that host the most international newcomers. Second, we have not found profound works on challenges affecting foreigners' study in Belarus and so the current study aimed to fill in this gap.

\section{Problems of the Research}

1. To identify challenges that complicated the education of international students in Belarus. 
2. To rank and analyze the problems of greatest concern.

3. To provide recommendations for university staff and administrators on how to better assist overseas students in coping with their problems.

\section{Methodology of the Research}

\section{General Background and Theoretical Framework of the Research}

Belarus is an ex-Soviet country and all educational programs are run here in Russian, which makes problems for those enrolees who cannot speak it. This also leads to the fact that more than half of international students in Belarus are originally from countries where Russian is spoken as a first or second language: Russia, Azerbaijan, Kazakhstan, etc. For those international students who cannot speak Russian, every college or university provides courses in the Russian language. In our study, language course students were chosen as the target population since the previous research has convincingly shown that foreigners who know the language of the host country do not experience significant adjustment problems (Yan \& Sendall, 2016).

The study draws on the theories of academic sojourners' adjustment and acculturation (Church, 1982; Siu, 1952). This theory focuses on interaction between distinct cultures which often results in numerous psychological, social, cultural, and other challenges for immigrants. In our case, this theory helped consider how academic sojourners would perceive their transitional journey to Belarus.

\section{Instrument and Procedures}

Inspired by the Sociocultural Adaptation Scale that was created by Ward and his colleagues for newcomer students (Ward \& Kennedy, 1999), we developed the International Student Problem Scale (ISPS) to rank the problems of international students in Belarus (cf. detailed research presented in Marinenko, 2015). As recommended (Harlacher, 2016), in the first phase of our study, we conducted preliminary interviews by asking 20 undergraduate students from the Belarusian-Russian University in Mogilev to identify problems that complicated their study. The interviewees mentioned a number of difficulties that generally could be divided into four categories: (a) psychological and health-related challenges, (b) social and cultural challenges, (c) educational challenges, (d) general living challenges.

The identified issues were included in the questionnaire (ISPS), that had two parts. The first part asked the international students to rate how concerned they 
were about the stated challenges using a six-point scale $(1=$ not at all concerned $/ 2=$ slightly concerned $/ 3=$ somewhat concerned $/ 4=$ moderately concerned $/ 5$ $=$ greatly concerned $/ 6=$ extremely concerned). The second part of ISPS requested the respondents to provide information on their age, gender and ethnicity.

In the second phase of our study we used expert assessment to estimate the developed ISPS. Since "the easier the questionnaire, the more useful and accurate the results will be" (Harlacher, 2016, p. 4), the final version of ISPS included challenges which received the highest validity indices, i.e. most experts considered these challenges relevant or very relevant for academic sojourners.

Before conducting the main survey, the developed ISPS was pilot-tested on a small sample of newcomer students of Belarusian-Russian University $(\mathrm{N}=40)$ to check its validity and reliability. The range of reliability statistics indicated a relatively high level of internal consistency: the overall Cronbach's alpha coefficient was .756 for 17 problems.

\section{Data Collection and Analysis}

The study was conducted in seven universities across Belarus and involved 300 Russian language course students who had lived in Belarus up to four months at the time of research. Such sample size gave us $95 \%$ confidence that the sampling error would be within 5\% (Cumming \& Calin-Jageman, 2017). Participation in the survey was voluntary and the respondents generally corresponded to all Belarusian sojourners in their main characteristics (see table 1).

Table 1. Description of Respondents' Background

\begin{tabular}{llc}
\hline & Characteristics & Respondents, \% \\
\hline \multirow{2}{*}{ Age } & $18-23$ & 88 \\
\cline { 2 - 3 } & Over 23 & 12 \\
\hline \multirow{2}{*}{ Gender } & Male & 86 \\
\cline { 2 - 3 } & Female & 14 \\
\hline Ethnicity & Turkmen & 68 \\
\hline & Chinese & 23 \\
\hline & Arabic & 8 \\
\hline
\end{tabular}

The data analysis included descriptive statistics: percentage, measures of central tendency (mean) and variability (standard deviation). Mean $(M)$ was used to determine the level of difficulty that international students experienced with each challenge from ISPS. The maximum possible $M$ for each issue was 6 (1-2.6 indi- 
cated a low level of difficulty, 2.7-4.3 indicated a moderate level, 4.4-6.0 indicated a high level). Standard deviation (SD) enabled us to determine the variability in the data.

\section{Results of the Research}

According to the data obtained, all challenges experienced by Belarusian sojourners were in the moderate or low levels, which in general meant that in spite of facing a significant number of problems, these students were quite positive about their studies in Belarus and did not intend to overestimate their problems (see table 2).

Table 2. Rating of Challenges by International Students in Belarus

\begin{tabular}{|c|c|c|c|c|c|c|c|c|}
\hline \multirow{2}{*}{ Challenge } & \multicolumn{6}{|c|}{ Respondents who rated,\% } & \multirow{2}{*}{ M } & \multirow{2}{*}{ SD } \\
\hline & 6 & 5 & 4 & 3 & 2 & 1 & & \\
\hline Homesickness & 15.7 & 26.3 & 17.0 & 5.0 & 16.7 & 19.3 & 3.61 & 1.79 \\
\hline Health disorders & 11.7 & 15.3 & 27.0 & 10.7 & 12.0 & 23.3 & 3.34 & 1.69 \\
\hline $\begin{array}{l}\text { Lack of understanding of } \\
\text { the Belarusian educational } \\
\text { system }\end{array}$ & 18.3 & 11.3 & 14.0 & 10.0 & 25.7 & 20.7 & 3.25 & 1.81 \\
\hline $\begin{array}{l}\text { Interaction with native } \\
\text { speakers }\end{array}$ & 15.0 & 14.7 & 18.7 & 10.6 & 13.7 & 27.3 & 3.25 & 1.81 \\
\hline $\begin{array}{l}\text { Loneliness and social } \\
\text { isolation }\end{array}$ & 5.0 & 16.0 & 20.0 & 13.7 & 18.0 & 27.3 & 2.94 & 1.6 \\
\hline $\begin{array}{l}\text { Foreign customs, traditions } \\
\text { and rules }\end{array}$ & 15.0 & 6.7 & 11.0 & 14.0 & 21.7 & 31.7 & 2.84 & 1.78 \\
\hline Climate in Belarus & 9.3 & 6.7 & 18.3 & 13.0 & 20.3 & 32.3 & 2.75 & 1.65 \\
\hline The ban on part-time work & 10.3 & 8.3 & 20.7 & 7.0 & 10.7 & 43.0 & 2.72 & 1.79 \\
\hline $\begin{array}{l}\text { Unfamiliar food, dietary } \\
\text { restrictions }\end{array}$ & 6.3 & 8.3 & 15.0 & 16.7 & 20.7 & 33.0 & 2.64 & 1.57 \\
\hline Depression & 7.3 & 7.7 & 13.0 & 18.3 & 11.7 & 42.0 & 2.55 & 1.64 \\
\hline Taking exams & 15.0 & 5.3 & 9.7 & 9.0 & 5.0 & 56.0 & 2.48 & 1.92 \\
\hline $\begin{array}{l}\text { Lack of effective learning } \\
\text { skills }\end{array}$ & 3.3 & 12.7 & 13.3 & 10.1 & 17.3 & 43.3 & 2.45 & 1.59 \\
\hline $\begin{array}{l}\text { Language proficiency insuf- } \\
\text { ficient for education }\end{array}$ & 5.0 & 6.0 & 11.0 & 13.3 & 25.7 & 39.0 & 2.34 & 1.48 \\
\hline Financial problems & 1.7 & 9.6 & 17.0 & 7.0 & 12.7 & 52.0 & 2.25 & 1.53 \\
\hline
\end{tabular}




\begin{tabular}{|c|c|c|c|c|c|c|c|c|}
\hline \multirow{2}{*}{ Challenge } & \multicolumn{6}{|c|}{ Respondents who rated,\% } & \multirow{2}{*}{ M } & \multirow{2}{*}{ SD } \\
\hline & 6 & 5 & 4 & 3 & 2 & 1 & & \\
\hline $\begin{array}{l}\text { Language proficiency insuf- } \\
\text { ficient for everyday life }\end{array}$ & 4.7 & 5.0 & 12.7 & 12.0 & 17.3 & 48.3 & 2.23 & 1.5 \\
\hline Discrimination issues & 1.7 & 5.0 & 10.7 & 12.3 & 9.7 & 60.7 & 1.95 & 1.37 \\
\hline Handling household chores & 5.3 & 7.3 & 6.7 & 3.0 & 12.7 & 65.0 & 1.95 & 1.57 \\
\hline
\end{tabular}

\section{Psychological and Health-Related Challenges}

Among all problems homesickness topped the list ( $M=3.61): 42 \%$ of the surveyed population was greatly, or extremely concerned about this issue. The $S D$ for homesickness showed a wide range of responses(from 1.82 to 5.4), which meant that the opinions of respondents varied regarding life in the new country without those close to them. Another issue of high concern was health disorders $(M=3.34)$. Only one out of four international students $(23.3 \%)$ did not worry about their physical state during study in Belarus. These findings were confirmed by our preliminary interviews when the participants complained about frequent colds, numerous aches and pains.

Loneliness and social isolation ranked third in the category and fifth out of all the 17 problems $(M=2.94): 21 \%$ of sojourners assessed it as a great or extreme challenge. Besides, $S D$ for this issue was the lowest in this group, which indicated that the participants' opinions tended to be similar and they were sad without those close to them. The psychological issue rated least important was depression $(M=2.55)$, as $42 \%$ of respondents answered "not at all concerned", which meant that although foreigners prioritized psychological and health-related problems, they did not consider them as a cause of deep emotional disturbance.

\section{Educational Challenges}

In the participants' view, the most challenging educational issue was the lack of understanding of the Belarusian educational system (M=3.25). Almost 30\% of the respondents agreed that they were greatly or extremely concerned about coping with it. Taking exams was the second significant challenge in the category $(M=2.48)$ : every fifth respondent rated this factor as a great or extreme problem. At the same time, more than half of the surveyed population did not worry about their exams, which resulted in the highest standard deviation in this set $(S D=1.92)$.

The next educational challenge was lack of effective learning skills $(M=2.45)$ : for $16 \%$ of respondents this factor caused extreme or great problems. Finally, the educational issue of least concern was language proficiency insufficient for education 
$(M=2.34)$, which caused a significant problem for only every tenth respondent. This can be explained as follows: all language course teachers use English to instruct beginners and the sojourners may not have considered that their Russian competence was insufficient for their studies.

\section{Sociocultural Challenges}

Among the barriers in dealing with an unfamiliar culture and a new society the sojourners were mostly challenged by interaction with native speakers $(M=3.25)$ : every third respondent $(29.7 \%)$ found this issue greatly or extremely problematic. The next issue in this category, foreign customs, traditions and rules $(M=2.84)$ united numerous specific problems that sojourners reported during the preliminary interviews: unclear rules of addressing and greeting in Russian, national prejudices, limitations in how to spend leisure time, sharing rooms, etc.

Language proficiency insufficient for everyday life ranked third among sociocultural challenges $(M=2.23)$. The standard deviation of this issue was quite low $(S D=1.5)$ which indicated that sojourners' opinions were generally close. Almost every second student very strongly disagreed that their language competence was not sufficient for daily communication. Finally, the sociocultural factor of least concern was discrimination issues: $60.7 \%$ of respondents never encountered such a hurdle during their study in Belarus.

\section{General Living Challenges}

The category of general living challenges combined the largest number (five) of all sojourners' problems, but despite this, it ranked last (the mean of this category was 2.46). The most challenging issue in this group was the climate in Belarus $(M=2.75 ; S D=1.65)$. The ban on part-time work caused a problem only for Belarusian sojourners, since the law forbade study-visa holders to look for employment and this issue ranked second in the category $(M=2.72)$. Unfamiliar food, dietary restrictions ranked second $(M=2.64 ; S D=1.57)$, which confirmed the results of preliminary interviews, where students complained about the lack and high cost of some products in Belarus. Financial problems $(M=2.25)$ also disturbed the international students, but its standard deviation was the lowest $(S D=1.53)$, which meant that many respondents had to cope with it. Finally, handling household chores had the lowest rating among general living problems $(M=1.95 ; \mathrm{SD}=1.57)$. 


\section{Discussion}

The findings revealed that international students in Belarus mostly suffered from psychological and health-related challenges. In the framework of theories of academic sojourners' adjustment and acculturation, these results emphasize that overseas students perceive their sojourn as a pattern of stress, isolation and loneliness and that they are often positioned as outsiders and marginalized (Spurling, 2006). The significance of the sojourners' stable psychological and physiological states during their study abroad was confirmed by other works (Borg \& Cefai, 2014). By contrast, our findings are inconsistent with some research which prioritized challenges of other sojourners (Sonari, 1994; Sam, 2001).

Of all the challenge areas considered in our study, homesickness was found to be the issue of most concern, as students in the study had spent a very short period in Belarus and may not have managed to adjust to their new way of living. The relevance of this problem for academic sojourners was also confirmed by other findings (e.g., Gebhard, 2012). The second issue of most concern for Belarusian sojourners was health disorders, and previous research documented numerous ailments during study abroad (Borg \& Cefai, 2014). Besides, overseas students in Belarus had to cope with other psychological problems like loneliness, social isolation and depression.

In our research, educational challenges ranked second, which concur with some other works where sojourners prioritized this type of difficulty (e.g., Alsahafi \& Shin, 2017). At the same time, these studies were conducted in English-speaking countries and Belarusian sojourners may not have taken their education seriously, namely, second language learning. The most problematic educational issue was lack of understanding of the Belarusian educational system, and international students in other countries had to cope with unclear college regulations, grading, etc. (Sonari, 1994). Belarusian sojourners also experienced difficulties with taking exams and lack of effective learning skills: independent work, using supportive and library facilities, etc. Language proficiency insufficient for education was, surprisingly, the educational factor of least concern for the sojourners.

The findings indicated that respondents experienced some aspects of cultural stress and social isolation, since they ranked sociocultural problems third. In this category sojourners mostly suffered from difficulty in interaction and communication with native speakers and foreign customs, traditions and rules. These results are in line with the findings of Carroll \& Ryan (2005) that entering a different culture leads to numerous problems in cooperative activities. Language proficiency insufficient for everyday life moderately disturbed the sojourners, since in most 
cases international students have little contact with local people and prefer to interact and communicate with their co-nationals outside the university (Kilinc \& Granello, 2003). The least problematic factor in the sociocultural category was discrimination issues, because Belarus still does not have a significant number of immigrants and locals are usually tolerant of them.

With regard to general living challenges, they ranked last in our study, which was supported by previous research (Sam, 2001). The problem of most concern in this category was the climate in Belarus, which can be easily explained by the location of the country. The next issue, the ban on part-time work, became a problem only for Belarusian sojourners, since in most countries international students are allowed to work in their free time. Unfamiliar food and dietary restrictions, financial problems, and handling household chores got the lowest ratings among general living challenges, as these can be considered personal and subjective issues.

\section{Implications}

The findings of this study are of practical importance as they highlight the importance of assistance for newcomer students and encourage educational institutions and their staff to facilitate their adjustment. In order to help sojourners avoid having problems and to help manage them, a supporting learning environment should be developed at every university or college (Carroll \& Ryan, 2005; Marinenko, 2015).

Thus, university or college administrators should pass initiatives to help international students by modernizing premises, facilities and equipment, improving their curricula and developing targeted study programs. Particularly, a special adjustment course may be developed for newcomer students (Yan \& Sendall, 2016). Regarding the outcomes of our study, this adjustment course should enhance sojourners' awareness by introducing them to various aspects of adaptation, activities to improve their physical and psychological state, treatment of common ailments, etc.

Since the study showed that international students were most concerned about their psychological and health-related problems, an additional position for a mentor teacher accompanying each group of newcomer students should be introduced (Yeh \& Inose, 2003). This specialist would be responsible for regular face-to-face and group meetings, monitoring sojourners' physical and emotional state, and running special workshops and seminars to address the challenges and experiences of study abroad. 
International and local students should also be involved in supportive activities for newcomers. So-called "peer programs" that pair newcomers with compatriots, or local students with English proficiency, for close communication and interaction have been proved to be an efficient supporting activity (Abe et al., 1998).

For the purpose of this research, an experiment was conducted to confirm the importance of support and assistance for sojourners. During the experiment, a number of procedures supporting international newcomers were developed and implemented in two Belarusian universities. As a result, the comparison analysis of students from control and experimental groups enabled us to experimentally demonstrate that supporting procedures help international students successfully overcome difficulties during their study abroad (Marinenko, 2015).

\section{Conclusions}

Belarusian sojourners faced a number of problems during their study. They were primarily concerned about psychological and health-related challenges: homesickness, health disorders, loneliness and social isolation. Despite the fact that the main activity of international students is education, the surveyed population ranked educational challenges second, and the main dilemmas in this category were lack of understanding of the Belarusian educational system and taking exams. Sociocultural problems, including communication with native speakers, understanding the foreign culture and others ranked third in the study. Finally, general living challenges such as the climate, the ban on part-time work, dietary restrictions, etc., were the least problematic category for the student newcomers.

The problems experienced by international students should encourage institutions of higher education to shape a supportive learning environment for them and motivate administrators, faculty, counsellors, international volunteers and local students to become more aware of investigating sojourners' needs and to provide facilitation and assistance.

\section{References}

Abe, J., Talbot, D.M., \& Geelhoed, R.J. (1998). Effects of a peer program on international student adjustment. Journal of College Student Development, 39(6), 539-547.

Alsahafi, N., \& Shin, S.-C. (2017). Factors affecting the academic and cultural adjustment of Saudi international students in Australian universities. Journal of International Students, 7(1), 53-73. 
Borg, C., \& Cefai, C. (2014). Stress, Health and Coping among International Students at the University of Malta. Malta: Centre for Resilience and Socio-Emotional Health, University of Malta.

Carroll, J., \& Ryan, J., Eds. (2005). Teaching international students: Improving learning for all. London: Routledge.

Church, A.T. (1982). Sojourner adjustment. Psychological Bulletin, 91(3), 540-572.

Cumming, G., \& Calin-Jageman, R.J. (2017). Introduction to the new statistics: Estimation, open science, and beyond. New York: Routledge.

Education in the Republic of Belarus (2016). Education in the Republic of Belarus: Statistical bulletin. Minsk: National Statistical Committee (in Russian).

Gebhard, J. G (2012). International students' adjustment problems and behaviors. Journal of International Students, 2(2), 184-193.

Harlacher, J. (2016). An educator's guide to questionnaire development. Washington: Institute of Education Sciences.

Kilinc, A., \& Granello, F.P. (2003). Overall life satisfaction and help-seeking attitudes of Turkish college students in the United States: Implications for college counsellors. Journal of College Counselling, 6, 56-69.

Marinenko, O.P. (2015). International students' pedagogical support at pre-university level. Mogilev: Belarusian-Russian University (in Russian).

Sam, D.L. (2001). Satisfaction with life among international students: An exploratory study. Social Indicators Research, 53(3), 315-337.

Siu, P.C.P. (1952). The sojourner. American Journal of Sociology, 58(1), 34-44.

Sonari, A.J. (1994). The nature and extent of the problems experienced by international students enrolled in an English language program (Doctoral dissertation). Oregon State University.

Spurling, N. (2006). Exploring adjustment: The social situation of Chinese students in UK higher education. Learning and Teaching in the Social Science, 3(2), 95-117.

Ward, C., \& Kennedy, A. (1999).The measurement of sociocultural adaptation. International Journal of Intercultural Relations, 23, 659-677.

Wenhua, H. \& Zhe, Z. (2013). International students' adjustment problems at university: a critical literature review. Academic Research International, 4(2), 400-406.

Yan, Z., \& Sendall, P. (2016). First year experience: How we can better assist first-year international students in higher education? Journal of International Students, 6(1), 35-51.

Yeh, C.J., \& Inose, M. (2003). International students' reported English fluency, social support satisfaction, and social connectedness as predictors of acculturative stress. Counseling Psychology Quarterly, 16(1), 15-28. 